\title{
Road Pricing with Autonomous Links
}

\author{
Lei Zhang and David Levinson
}

\begin{abstract}
This research seeks to examine road pricing on a network of autonomous highway links. "Autonomous" refers to the links' being competitive and independent and having the objective of maximizing their own profits without regard for either social welfare or the profits of other links. The principal goal of this research is to understand the implications of the adoption of road pricing and privatization on social welfare and the distribution of gains and losses. The specific pricing strategies of autonomous links are evaluated first under the condition of competition for simple networks. An agent-based modeling system is then developed; it integrates an equilibrated travel demand, route choice, and travel time model with a repeated game of autonomous links setting prices to maximize profit. The levels of profit, welfare consequences, and potential cooperative arrangements undertaken by autonomous links are evaluated. By studying how such an economic system may behave under various circumstances, the effectiveness of road pricing and road privatization as public policy can be assessed.
\end{abstract}

Roadway congestion, air pollution from cars, and the lack of resources to finance new surface transportation options challenge many nations. Road pricing, the practice of charging users a monetary toll in addition to the "cost" of time spent traveling, has been suggested as a solution to these problems. Although tolls are common on certain expensive facilities such as tunnels and bridges, they are less common on streets and highways. However, a new generation of private toll roads are being deployed, most recently SR-91 in southern California and the Dulles Greenway in northern Virginia. There have been a few trials of areawide pricing schemes, such as in Singapore and London, and many other schemes have been proposed but not implemented. The combination of private and competing toll roads, ubiquitous over an area, would represent a comprehensive market-oriented approach to urban transportation problems, but its impacts are unclear. This research seeks to examine road pricing on a network of autonomous highway links with the goal of understanding the social welfare and equity implications of widespread adoption of road pricing and privatization under various circumstances. "Autonomous" refers to the links' being competitive and independent and having the objective of maximizing their own profits without regard for either social welfare or the profits of other links, though possibly being subject to regulatory constraints. The basic approach taken is to begin with the link as the most elemental unit of analysis and aggregate to more complex interactions, including revenue and cost sharing.

A realistic network of highway links is not, in the economists' terminology, perfectly competitive. Because a link uniquely occupies space, it attains some semblance of monopoly power. Although in

Department of Civil Engineering, University of Minnesota, 500 Pillsbury Drive SE, Minneapolis, MN 55455.

Transportation Research Record: Journal of the Transportation Research Board, No. 1932, Transportation Research Board of the National Academies, Washington, D.C., 2005, pp. 147-155. most cases users can switch to alternative links and routes, those alternatives will be more costly to the user in terms of travel time. Theory suggests that excess profits will attract new entrants into a market, but the cost of building a new link is high, indicating barriers to entry not easily overcome.

Although roads are generally treated as public goods, they are both competitive when congested and excludable. These factors indicate that it is feasible to consider them for privatization. Several advantages are often associated with privatization: increasing the efficiency of the transportation system through road pricing, providing incentives for the facility operator to improve service through innovation and entrepreneurship, and reducing the time and cost of building and expanding infrastructure.

Most trials of road pricing suppose either tolls on a single facility, or areawide control. Theoretical studies assume marginal cost pricing on links and do not discuss ownership structure. However, in other sectors of the economy, central control of pricing through either government ownership or regulation has proven to be less effective than decentralized control for serving customer demands in rapidly changing environments. Single prices systemwide do not provide as much information as link-specific prices. Links that are priced only at marginal cost, the optimal solution in a first-best, perfectly competitive environment, constrain profit. Although excess profit is not socially optimal in the short term, over the longer term, it attracts capital and entrepreneurs to that sector of the economy. New capitalists will both invest more in existing technology to refine its deployment and enter the sector as competitors, trying to gain from a spatial monopoly or oligopoly. Furthermore, new capitalists may also innovate and thereby change the supply (and demand) curves in the industry.

By examining road pricing and privatization from a decentralized point of view, the issues associated with a marketplace of roads can be more fully explored, including short- and long-term distributional consequences and overall social welfare. The main contribution of this research will be to approach the problem from a theoretical and conceptual level and through the conduct of simulation experiments. Specifically, an agent-based simulation model is developed in this study that incorporates travel demand estimation, road maintenance and construction cost functions, pricing and financing strategies of autonomous links, and network performance evaluation. The simulation model considers both short-term traffic equilibrium and long-term supply and demand equilibrium in a highway network; it therefore more completely assesses the consequences of alternative ownership structures and pricing strategies.

\section{LITERATURE REVIEW}

Gomez-Ibanez and Meyer (1) have reviewed transportation privatization at an empirical level, though the cases of roadway privatization are few and not entirely successful. Even if roadways were privatized, it is unlikely that their price structure would be left entirely to the 
private sector. In many ways, roadways are natural monopolies, in that their provision and use has a declining average cost (aside from congestion effects). The proposed model contains within it several different forms of networks. Most obvious is the transportation network as a physical system, which has been well developed in the transportation literature (2). Boyce et al. (3) investigated the optimal network problem from a global perspective and developed algorithms based on optimal subset selection, which were later modified and applied to medium-sized networks by Rothengatter (4). In the model proposed in this paper, the links are autonomous and can interact with each other. This provides a second level of network: an economic network that considers coordination between firms (links). Johansson et al. (5) describe various economic networks from an empirical viewpoint, while Nagurney (6) provides a computational framework that links analysis of economic networks (supplier-customer relationships) with algorithms developed for the analysis of physical networks. Economides (7) compares the economic structure of networks with vertically related industries. Because the model being described here is inherently dynamic, it may not contain a neat equilibrium solution. A modeling approach using cellular automata suggests specifying simple rules and allowing the system to evolve (8). The extent to which links can set prices following those simple rules and still achieve a maximum profit level can be ascertained with the model. Recently, Verhoef and Rouwendal explored interrelations between pricing, capacity choice, and financing in transportation networks using a small network model (9).

Although the focus of this study is on the economic interactions between links and the consequences of price strategies, the travel demand and travel time components of the model need to be specified (10-12). The monetary costs of infrastructure provision, user operating costs, and social costs on highways as a function of flow have recently been estimated by several studies $(13,14)$, and these costs will be considered by the links in profit maximizing and the prices they charge. They need to be integrated and solved in both traffic equilibrium (2) and long-term supply-demand equilibrium. Zhang and Levinson developed an exploratory agent-based travel demand model (15). However, in its present form, the model cannot perform all functions of trip-based demand models.

\section{AGENT-BASED NETWORK DYNAMICS MODEL}

Few researchers have considered the process of transportation network growth (or decline) at the microscopic level, although longterm transportation network dynamics are important for assessing alternative pricing policies and institutional structures. Analytical models of network growth are not practical except under simple, idealized conditions, represented by very small networks and analyzed using the principles of transportation engineering, microeconomics, game theory, and industrial organization. Zhang and Levinson proposed a model of transportation network growth with average cost pricing and myopic investment rules that demonstrates the feasibility of an agent-based simulation approach for transportation-related policy analysis (16). Their simulation model is extended in several ways in this study.

An overview of model components and their interconnectivity is shown in Figure 1. A travel demand model predicts link-level flows based on network, socioeconomic, and demographic information. Based on the demand forecasting results, links calculate revenues and costs. An investment module then operates and causes annual supply changes, producing an updated network. The transportation network is represented as a directed graph that connects nodes with directional arcs (links). The standard notation convention for directed graphs is adopted for the following presentation on the details of mathematical formulations of those submodels. The directed graph is defined as $G=\{N, A\}$, where $N$ is a set of sequentially numbered nodes and $A$ is a set of sequentially numbered directed arcs.

\section{Notation}

Notation used is as follows:

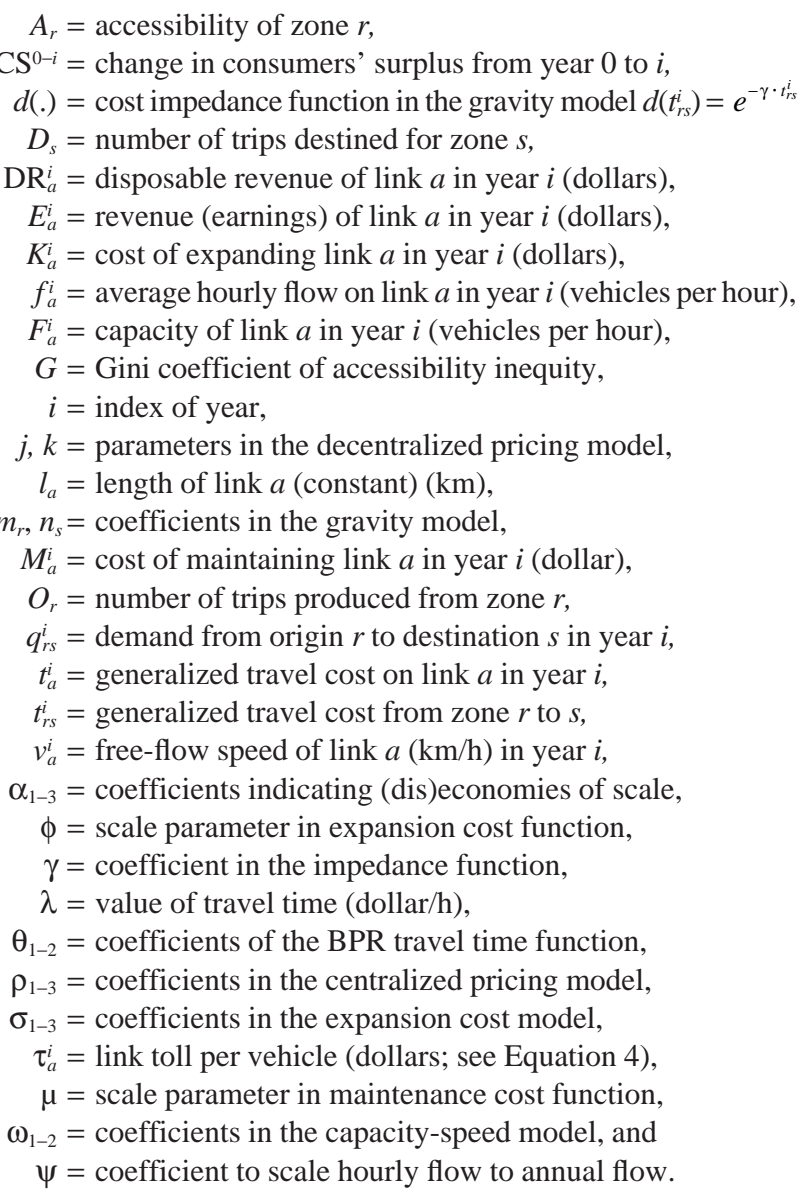

\section{Travel Demand}

A traditional four-step model is specified to estimate travel demand at the link level, taking exogenous land use, socioeconomic variables, and the existing network as inputs. Although the four-step model serves well for demonstration purposes in this paper, future studies should use more advanced travel demand models. For instance, combined travel demand models address inconsistencies in the sequential model by solving all steps in a coherent equilibrium (17). Activitybased approaches (18) and agent-based microsimulation (15) improve behavioral representation in travel demand models. A zone-based regression structure is used for trip generation. The origin-destination (O-D) cost table obtained from the previous year's traffic assignment is used for trip distribution in the current year based on a doubly constrained gravity model $(19,20)$.

$q_{r s}^{i}=m_{r} O_{r} n_{s} D_{s} \cdot d\left(t_{r s}^{i}\right)$ 


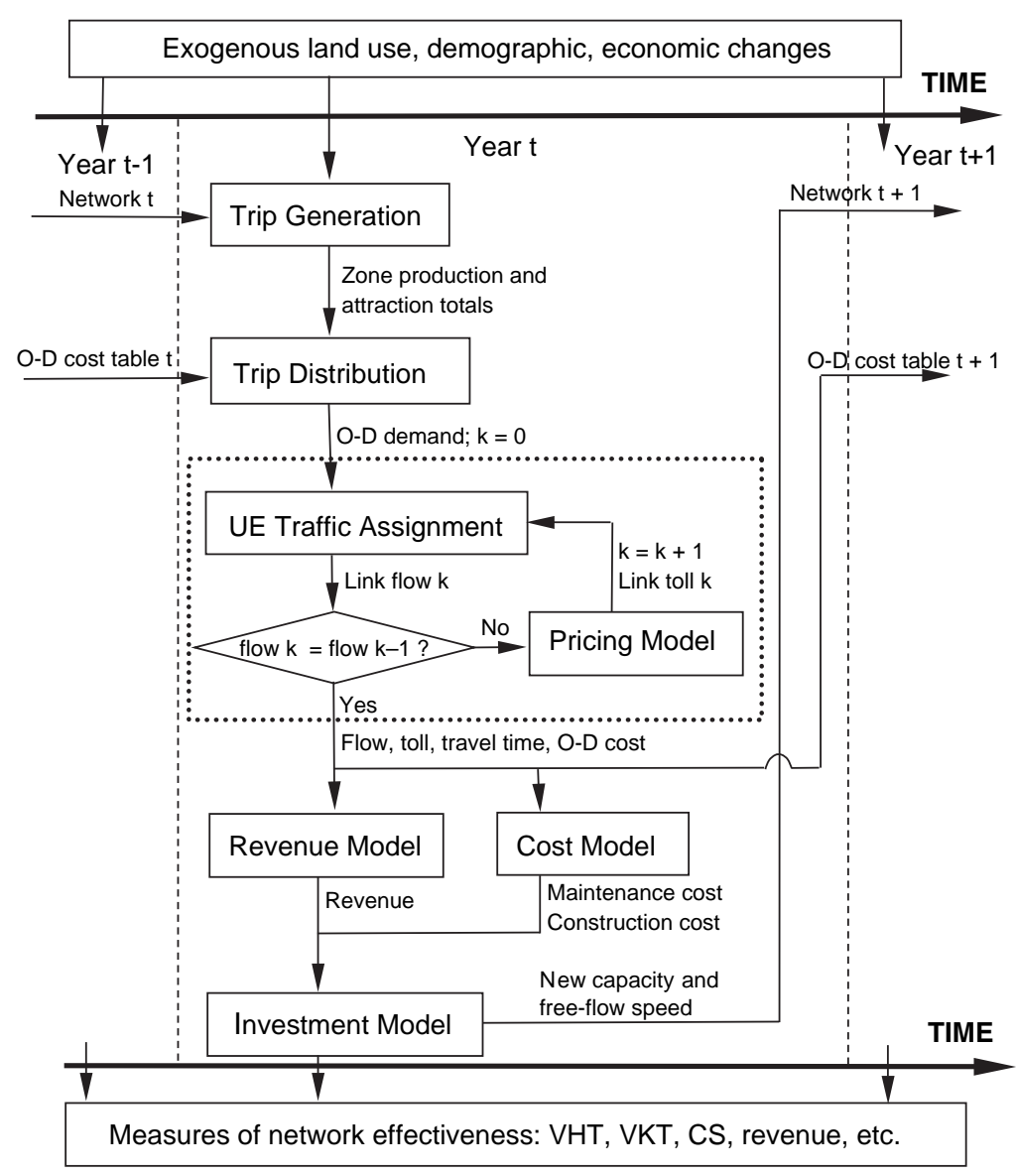

FIGURE 1 Flowchart of simulation model (UE = user equilibrium).

The resulting O-D table is loaded onto the current year transportation network through the origin-based user equilibrium traffic assignment algorithm (OBA) (21). The generalized link cost function comprises two parts: a BPR travel time component and a vehicle toll.

$$
t_{a}^{i}=\lambda \frac{l_{a}}{v_{a}^{i}}\left[1+\theta_{1}\left(\frac{f_{a}^{i}}{F_{a}^{i}}\right)^{\theta_{2}}\right]+\tau_{a}^{i}
$$

The OBA algorithm derives link flows at user equilibrium and generates a new O-D cost table that will be used for trip distribution in the next year. In the traffic assignment step, if the relative excess travel cost is less than 0.001 , the Wardrop user equilibrium (22) is considered to be satisfied.

\section{Revenue and Cost Functions}

Revenue is collected individually by autonomous links in a form of vehicle toll. The annual revenue is simply the product of the toll and annual flow. The amount of the toll depends on the pricing strategy adopted by an autonomous link agent. Therefore, the following revenue equation is proposed:

$E_{a}^{i}=\tau_{a}^{i} \cdot\left(\psi \cdot f_{a}^{i}\right)$

The link maintenance cost function has two determining factors in a Cobb-Douglas form: link length and capacity. It costs more to main- tain a link at its current level of service if the link is longer and carries heavier flow.

$M_{a}^{i}=\mu \cdot\left(l_{a}\right)^{\alpha_{1}}\left(F_{a}^{i}\right)^{\alpha_{2}}$

Link expansion cost is considered a function of link length, existing capacity, and additional capacity to be expanded. It is more expensive to expand a unit capacity on a link with higher existing capacity.

$K_{a}^{i}=\phi \cdot\left(l_{a}\right)^{\sigma_{1}} \cdot\left(F_{a}^{i}\right)^{\sigma_{2}} \cdot\left(F_{a}^{i+1}-F_{a}^{i}\right)^{\sigma_{3}}$

\section{Investment Rules}

\section{Decentralized Autonomous Links}

Two assumptions are made concerning the investment rules adopted by autonomous links. First, it is assumed that the system is closed and that all revenue will be spent to either maintain or expand links. Second, there is no incentive for links to save revenue (i.e., revenue accumulated in a year will be used in that year). These two assumptions could be relaxed if a bank agent is included in the simulation model and provides an endogenous interest rate. Disposable revenue is defined as the difference between total revenue and maintenance cost.

$\mathrm{DR}_{a}^{i}=E_{a}^{i}-M_{a}^{i}$ 
Disposable revenue of a link is used to expand that link. Therefore, one can substitute $\mathrm{DR}_{a}^{i}$ for $K_{a}^{i}$ in Equation 5 and solve for the new capacity in year $i+1$. It is possible that the disposable revenue of a link is negative because of previous overinvestment or competition. In that case, the link will shrink in the next year because total revenue falls short of maintenance cost. Note that this autonomous investment rule is myopic because links care only about themselves, ignore network effects, and spend all revenue immediately.

A capacity change is usually associated with a concurrent change of free-flow speed. Vehicles are able to travel at faster speeds on a wider road with less impedance. Free-flow speed and capacity data used by the Twin Cities Metropolitan Council in its regional transportation planning model on more than 10,000 roadway sections were used to study the correlation between speed and capacity. A log-linear model is specified and estimated. $R^{2}$ of the model is 0.7 , and both coefficients are statistically significant at level 0.01 .

$v_{a}^{i+1}=\omega_{1}+\omega_{2} \cdot \ln \left(F_{a}^{i+1}\right)$

With updated link capacity and free-flow speed, some factors influencing travel behavior, such as link travel time and link toll, will change. These supply shifts, combined with preference, economical growth, and demographical changes, give rise to the emergence of a new demand pattern.

\section{Centralized Government Control}

In contrast to decentralized investment decisions made by autonomous links, revenues collected on all links may be pooled together, and a central government agency may make all investment decisions. For comparison purposes, a centralized investment rule is examined. It is assumed that the central government can always adjust its pricing policy (see next section) so that total network revenue is higher than maintenance cost. The remaining network revenue is spent to expand existing links based on benefit-cost ratios.

The maximum possible benefit-cost ratio $\left(\mathrm{BC}_{\max }\right)$ of expanding each link, as well as the corresponding optimal amount of expansion, is computed based on Equation 5 and the following assumptions: (a) Traffic increases by $4 \%$ every year; $(b)$ interest rate is $3 \%$; (c) value of time is $\$ 10 / \mathrm{h}$ for all users; $(d)$ the planning horizon is 30 years; $(e)$ only local travel time benefits are considered. The network revenue is used to expand the link with the highest $\mathrm{BC}_{\max }$. Then, the link with the next-highest $\mathrm{BC}_{\max }$ is expanded until the centralized revenue is exhausted. Similarly, a capacity change results in a new free-flow speed according to Equation 7.

\section{ROAD PRICING}

\section{Decentralized Autonomous Links}

Autonomous links seek to maximize their short-run profits in a competitive market. Because travel demand is elastic with respect to price, the profit-maximizing price is constrained by the market. Competing links also restrict the price that an autonomous link can charge and still maximize profits. It is anticipated that each link will have an objective function for profit maximization. However, depending on assumptions of whether the firm perfectly knows market demand and how the firm treats the actions of competitors, the Nash equilibrium solution to the problem may not be unique or even exist.
Whether this system converges upon an equilibrium solution and whether that solution is unique are important questions that this research addresses.

The incompleteness of information is profound in the market comprised of noncooperative competing autonomous links. The situation of incomplete information is further aggravated by the fact that the demand function on one link depends on its previous investment decisions and the pricing-investment decisions made by its competing and complementary links. How do autonomous links determine the profitmaximizing price in this dynamic situation? Underlying the decision of each autonomous link is an objective function, profit maximization given certain amounts of information, and a behavioral rule that dictates the amount and direction of price changes depending on certain factors. Once a link has found a toll that it can neither raise nor lower without losing profit, it will be tempted to stick with it.

Therefore, it is assumed that links try to achieve profit maximization in this interdependent and evolving system by adjusting their prices iteratively based on available information about link travel demand. In each iteration, a link determines its price based on prices and profits in the previous $k$ iterations. Specifically, a link fits a quadratic curve in the profit-price domain. If the curve is concave, the new price is identified at the maximum point. If the curve is convex, the price corresponding to the maximum profits in the previous $k$ iterations will be marked up or down by $j$ percent to form the new price (see Figure 2). This pricing rule helps the link maximize profit and keep the price changes small. A myopic pricing rule is plausible when demand functions are unknown to autonomous links. The assumption of unknown demand will be checked in the later simulation experiment. If the demand functions turn out to be relatively stable from iteration to iteration (i.e., a reasonably accurate demand curve can be estimated after several trials), the proposed pricing rule needs to be revised because there are obviously better pricing strategies for profit-maximizing links.

However, a more intelligent link may realize that although it may have found a local maximum, because of the nonlinearities that make up a complex network, it may not be at a global maximum. Furthermore, other links may not be so firmly attached to their decision, and a periodic probing of the market landscape by testing alternative prices is in order. This too requires rules and should be explored in future studies.

It should be noted that a homogenous user group is assumed in this study. Several recent studies show that the ignorance of user heterogeneity and the possibility of product differentiation cause underestimation of the benefits of road pricing and decentralized control (23-25). The network growth model described above needs to use a multiclass travel demand model to account for variation in value of time, which should be pursued in future studies.

\section{Centralized Government Control}

Under centralized control, users pay a distance-based toll for using the roads. This method is similar to a fuel tax except that the variation of fuel efficiency among vehicles is ignored. Free-flow speed is also included in the centralized pricing model because it also affects fuel efficiency and hence the actual prices that users pay.

$\tau_{a}^{i}=\rho_{1} \cdot\left(l_{a}\right)^{\rho_{2}} \cdot\left(v_{a}^{i}\right)^{\rho_{3}}$

Note that even a link-based congestion pricing rule would improve the efficiency of centralized control. Equation 8 is selected 


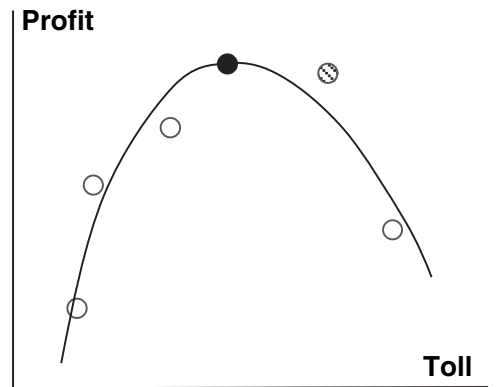

(a)

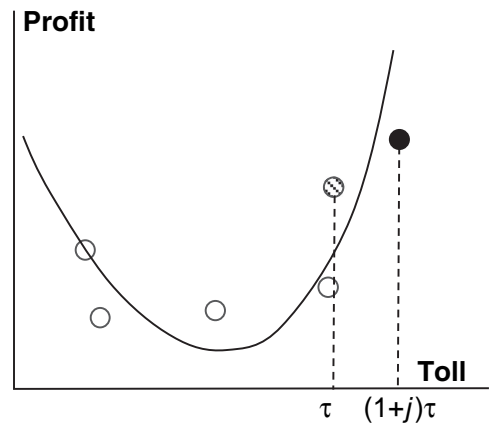

(b)

\section{Prices in previous The price in previous $k$ iterations $k$ iterations corresponding to maximum profit \\ New price}

FIGURE 2 Pricing rule for autonomous links: (a) concave and $(b)$ convex.

because it better describes the current road financing practice in most areas.

\section{SIMULATION EXPERIMENTS}

So far, a complete cycle of the network evolution process has been modeled, and all elements in the flowchart have been specified. This demand-cost-pricing-investment cycle repeats itself year after year. It is possible to simulate the growth of the network with alternative pricing and investment policies. Measures of effectiveness collected from these agent-based simulation experiments are valuable for policy evaluation. The issue of whether a transportation network evolves better under centralized or decentralized control can be explored.

\section{Estimation of Model Coefficients}

Most coefficients in the specified network dynamics model are estimated based on empirical data in the Twin Cities (Minneapolis and St. Paul, Minnesota). Estimation of the cost function (Equations 4 and 5) is documented in detail in Levinson and Karamalaputi (14). Several power coefficients are determined based on the authors' best knowledge of economies or diseconomies of scale in transportation network dynamics. A summary of estimation methods and results is shown in Table 1.

\section{Measures of Effectiveness}

The network dynamics model provides the following information for each year in the evolutionary process: population and activities at the zone level; demand, travel time, and generalized travel cost at the O-D level; and flow, capacity, speed, travel time, and toll at the link level. This information is used to develop several measures of effectiveness (MOE) for the evaluation of network performance over time. Total vehicle hours traveled (VHT) and total vehicle kilometers traveled (VKT) are fairly standard network MOEs. The change in consumers' surplus between year 0 and year $i$ is approximated by the rule of half. Total net social benefit is the sum of changes in consumers' surplus and toll revenue.
$\mathrm{CS}^{0-i}=\sum_{r} \sum_{s} \frac{1}{2}\left(q_{r s}^{i}+q_{r s}^{0}\right) \cdot\left(t_{r s}^{0}-t_{r s}^{0}\right)$

Accessibility to activities for residents in zone $r$ is

$A_{r}=\sum_{s} D_{s} \cdot d\left(t_{r s}\right)$

That equity may be ignored is a concern in a privatized network in which toll revenue is the primary financing source. The Gini coefficient is used to measure the inequity of accessibility among different network zones, which falls between 0 (perfectly equitable) and 1 (perfectly inequitable). If the results show degraded equity with autonomous links, it is necessary to identify winners and losers.

$G=\frac{\sum_{r} \sum_{s}\left|A_{r}-A_{s}\right|}{2 N \sum_{r} A_{r}}$

TABLE 1 Coefficients in Simulation Experiments

\begin{tabular}{lrl}
\hline Parameter & Value & Source \\
\hline$\lambda$ & 10 & Empirical finding \\
$\theta_{1}, \theta_{2}$ & $0.15,4$ & BPR function \\
$\gamma$ & 0.1 & Empirical finding \\
$\rho_{1}, \psi, \phi$ & 1 & Scale parameters \\
$\rho_{2}$ & 1 & CRS of link length \\
$\rho_{3}$ & 0.75 & DRS of level of service \\
$\mu$ & 20 & Scale parameter \\
$\alpha_{1}$ & 1 & CRS of link length \\
$\alpha_{2}$ & 1.25 & DRS of capacity \\
$\sigma_{1}$ & 0.5 & Empirical finding \\
$\sigma_{2}$ & 1.25 & Based on empirical findings \\
$\sigma_{3}$ & 1 & CRS of additional capacity \\
$\omega_{1}, \omega_{2}$ & $-30.6,9.8$ & Empirical estimates \\
$k, j$ & $5,0.2$ & Link behavior assumption \\
\hline
\end{tabular}

$\mathrm{BPR}=$ Bureau of Public Roads; $\mathrm{CRS}=$ constant returns to scale; $\mathrm{DRS}=$ decreasing returns to scale. 
The average and distributional properties of link price and capacity will also be examined because they reveal the degree of network hierarchy that may differ under different institutional structures. Profitability for autonomous links is also of higher interest for its implications on viability of decentralized control.

\section{Sample Network}

The simulation system can be applied to any realistic roadway network. The execution time is mainly determined by the convergence speed of the traffic assignment model. A 10-by-10 grid network (100 nodes and 360 links) is used herein to explore the consequences of road pricing under alternative institutional structures. The same initial condition is specified for both simulation scenarios: centralized government control and decentralized autonomous links. All links in the grid network are $4 \mathrm{~km}$ in length and have an initial capacity of 735 vehicles per hour (this value corresponds to a onelane road according to a regression analysis using the capacity and number-of-lane data in the Twin Cities). The initial network is heavily congested, with an average volume capacity ratio of 0.8 and an average speed of about $10 \mathrm{~km} / \mathrm{h}$ (because road pricing and privatization are usually not considered for uncongested networks). The initial land use is uniform among all 100 network zones, with 10,000 trips originating from and destined for each zone, respectively. Convergence of the simulation model can be measured directly by the number of expansion activities in the network. Under centralized control, the network achieves the long-run supply-demand equilibrium if the total revenue is equal to the total required maintenance cost. With autonomous links, the equilibrium is achieved when the revenue is equal to the maintenance cost on each link.

\section{RESULTS}

The long-term supply and demand in the grid network seem to equilibrate under both centralized and decentralized control. All links are expanded at the beginning of the evolutionary process because of initial congestion. After about 70 iterations (or years), a stable equilibrium is achieved under centralized control (see Figure 3). It takes longer for the scenario with autonomous links to arrive at an exact equilibrium, which is expected. Although there are still road expansions after 100 iterations, those expansions are characterized by extremely small changes in capacity. By examining the evolution of link prices, we can better observe the equilibrating process with autonomous links. When all links are privatized and start to make their own pricing decisions at iteration 0 , there is a fast increase in link prices because of heavy congestion. After about 15 years of significant capacity expansion financed by abundant toll revenue, links must reduce their prices to maximize profits. The average link price continues to drop and eventually stabilizes itself around \$2.5 after more than 80 iterations. There are still instabilities in the network in that any changes in individual pricing decisions may cause the system to fluctuate through ripple effects.

It is important to construct and understand link travel demand curves, which determine the pricing strategies autonomous links are likely to follow. The demand information at the link level is also valuable for the evaluation of alternative organizational structures for road financing and pricing. The two graphs in Figure 4 are created by aggregating flows and generalized travel costs of all links in all simulation iterations. Under centralized control in which prices are strictly determined by the length and the level of service of individual links, a linear relationship exists between demand and price. There are

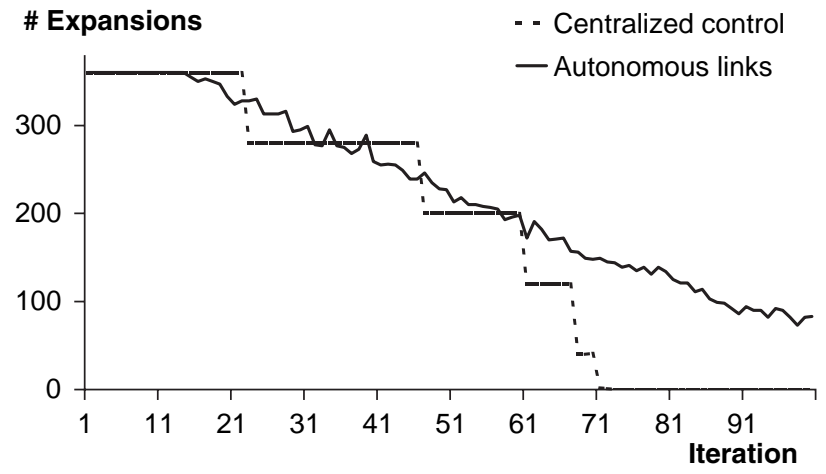

(a)

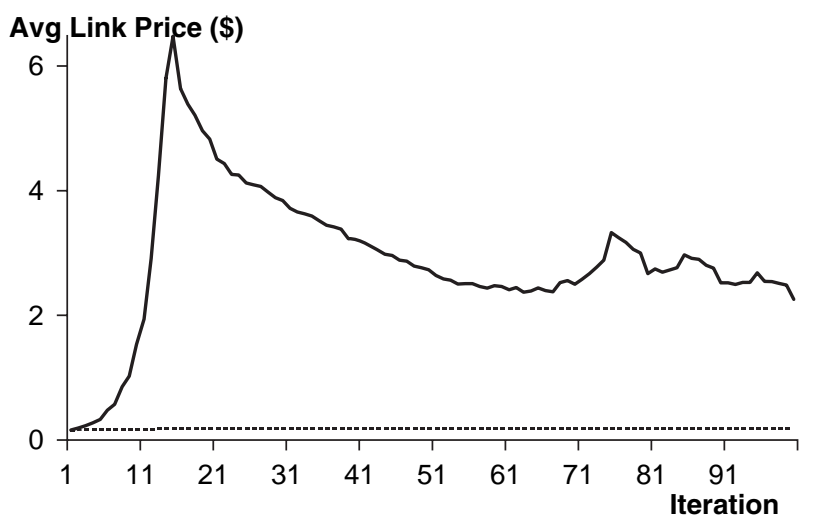

(b)

FIGURE 3 Convergence properties.

several parallel straight lines in Figure $4 a$ because links naturally evolve into five categories based on their locations in the network. However, with autonomous links making pricing decisions noncooperatively, the variation of demand at the same price level is so enormous that it is almost impossible for a link to identify the theoretically best price. The myopic pricing rule is reasonable given these results. With such a level of uncertainty and interdependency, links may be forced to adopt practical pricing strategies based on available information accumulated in their previous trials. Another implication is that in a situation in which several private profit-maximizing links compete with many public roads managed by a centralized government, it should be possible and rewarding for those autonomous links to estimate demand with a reasonable degree of accuracy.

Another interesting question is whether a set of autonomous competing links is a viable institutional structure for road financing and pricing. Can all links make and sustain a profit? The answer is negative if links do not properly manage their revenue. The number of links that can manage to generate a positive profit continues to drop over the years (see Figure 5). At the end of the simulation, only about 100 links still make money, whereas more than 200 others lose money. This is because autonomous links overinvest early in the evolutionary process when high prices bring in significant revenue, and they suffer high maintenance costs later on. This undesirable situation can be avoided by using a price ceiling regulation or heavy regulation on road expansions. Autonomous links should also be advised to use toll revenue to invest other sectors with a potentially higher rate of return. The overinvestment phenomenon under decentralized control could be partly attributed to the assumption that autonomous links 


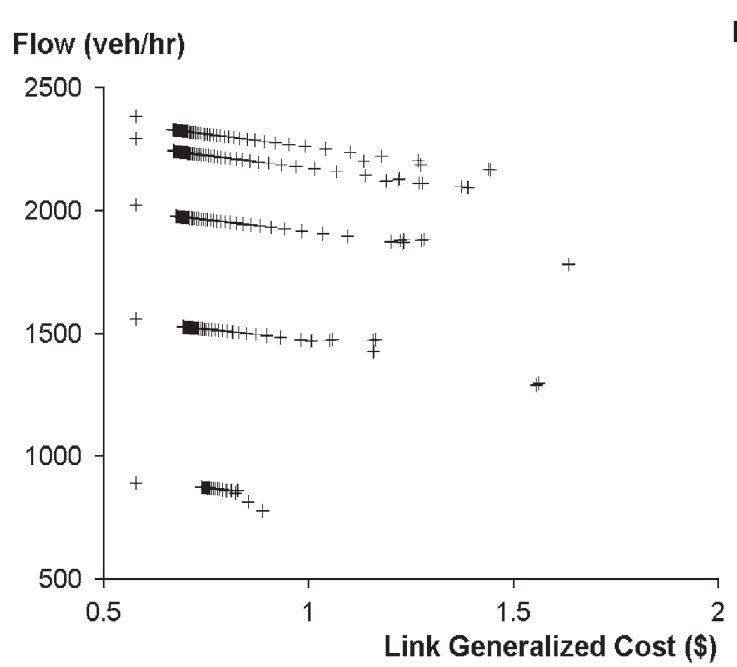

(a)

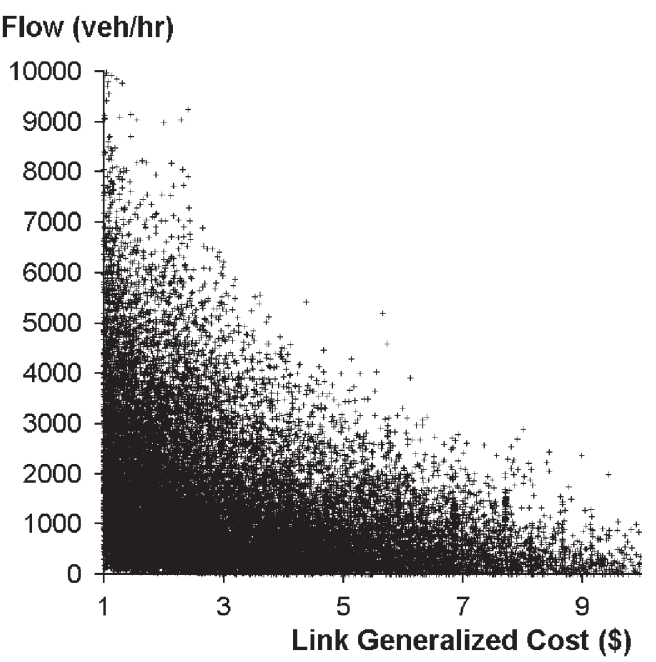

(b)

FIGURE 4 Link demand functions: $(a)$ centralized control and $(b)$ autonomous links.

expand capacity until short-run profit is zero. Future studies may develop more intelligent investment rules under decentralized control by modeling learning behavior. An interesting note is that, historically, overinvestment in capacity or a specific transportation technology is often related to decentralized control and competition (e.g., the U.S. railroad industry in the 19th century). Figure 6 presents the equilibrium tolls and capacity under both ownership structures. The existence of spatial monopoly is evident: the autonomous links at the corners and on the edges face less competition and lower demand elasticity, whereas links in the center must charge low tolls because of the existence of many parallel competitors.

Hierarchy has been long observed in road networks. Most roads have low capacity and carry low flows, whereas only a few roads are expanded to very high capacities and carry the bulk of traffic. Many believe road hierarchy is designed intentionally by planners. The results presented in Figure 6 clearly suggest that such structure also emerges in a free market driven purely by profit-maximizing behavior. A hierarchical structure is usually more efficient but has serious reliability and vulnerability problems. This infrastructure design issue is addressed in Zhang and Levinson (26).

As stated previously, one of the most important tasks of this study was to examine the welfare implications of road pricing with autonomous links. Various measures of network effectiveness developed in the previous section are computed for both centralized con-

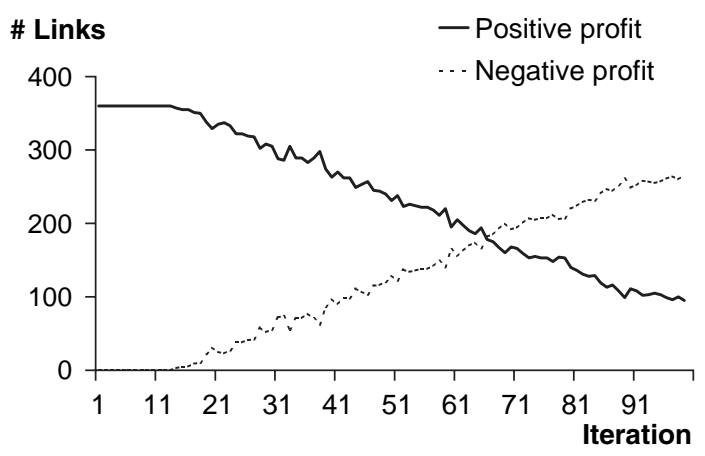

FIGURE 5 Profitability of autonomous links. trol (CC) and autonomous links and are summarized in Figure 7. Traditional network efficiency measures favor privatization. Average network travel speed is consistently higher with autonomous links over time (total VKT is comparable between the two scenarios, whereas total VHT is lower with autonomous links). Accessibility is, however, lower with autonomous links because faster speed is achieved mainly by pricing some users off the roads or forcing them to travel shorter distances. According to the computed changes in consumers' surplus, consumers actually gain more under CC than with autonomous links. The changes in CS are negative because the base case CS is calculated with the assumption of free-flow speed. On the supply side, autonomous links collectively charge much more to the users than does a central government agency, as shown by the revenue comparison. Net social benefit, defined as the sum of toll revenue and monetized changes in CS, is also smaller with autonomous links than under CC. The reason that the pricing strategy of autonomous links is inferior to completely regulated pricing under $\mathrm{CC}$ is manifold. First, the road market is not perfectly competitive. Spatial monopoly exists and some links (e.g., those near the corners of the grid network) are more dominant than others. Second, autonomous links do not have reliable demand information because of intractable spatial dependencies on competing and complementary links. In the simulation experiment, this lack of information leads to myopic nonoptimal pricing behavior. Third, autonomous links adopt myopic investment behavior because of a lack of foresight that leads to overinvestment. Finally, in the proposed model, links are not allowed to cooperate or consolidate into more efficient structures. Revenue or cost sharing may be beneficial for individual links and the system as a whole.

Another observation is that the network is less equitable with autonomous links. The Gini coefficient is significantly higher in a privatized market. Therefore, the equity issue should be addressed when road pricing with autonomous links is considered. Some kinds of "basic access" criteria may improve equity but require government intervention.

\section{CONCLUSIONS}

This research develops an agent-based simulation model to study the problem of road pricing on a highway network composed of independent, profit-maximizing links. It addresses some issues around road 


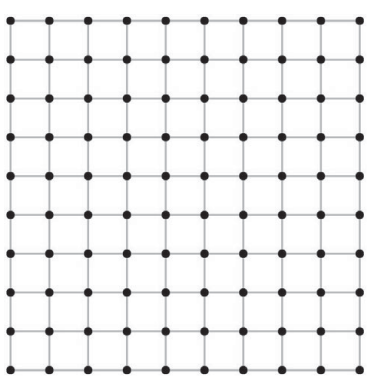

(a)

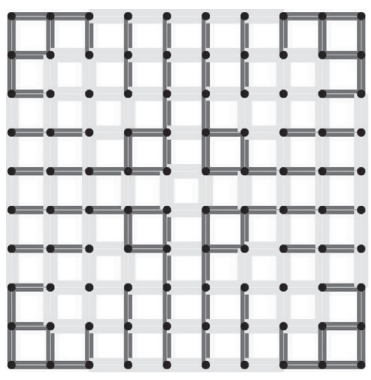

(c)

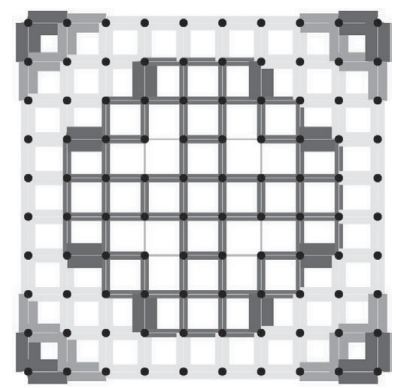

(b)

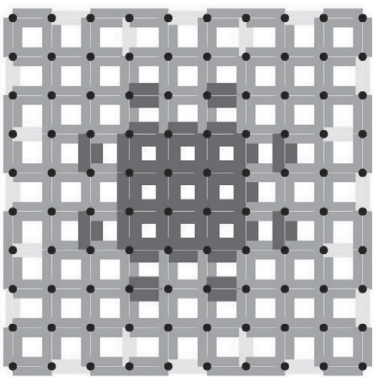

(d)
Toll (\$)

- $0-0.5$

0.5-1

$1-2$

2-4

$>4$

FIGURE 6 Equilibrium tolls and capacity: (a) centralized toll, $(b)$ decentralized toll, $(c)$ centralized capacity, and $(d)$ decentralized capacity.

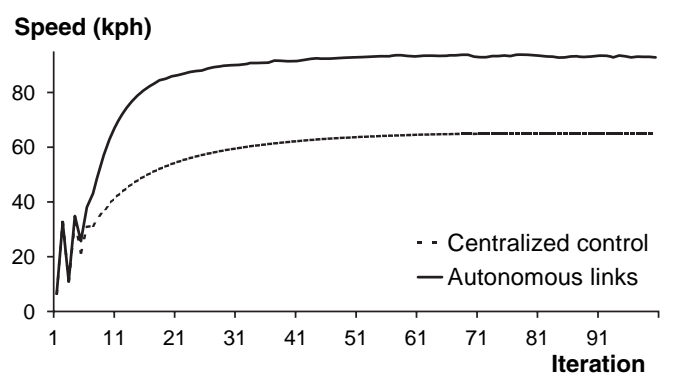

(a)

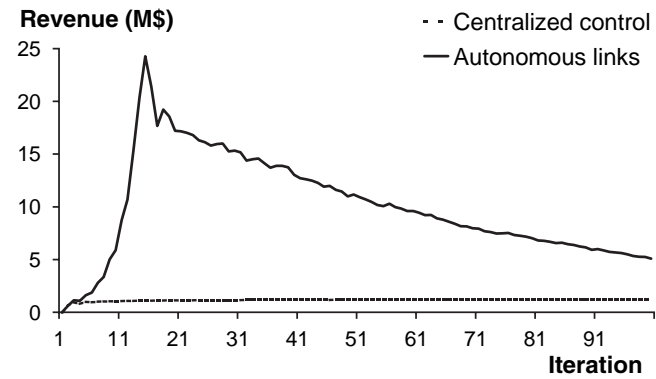

(c)

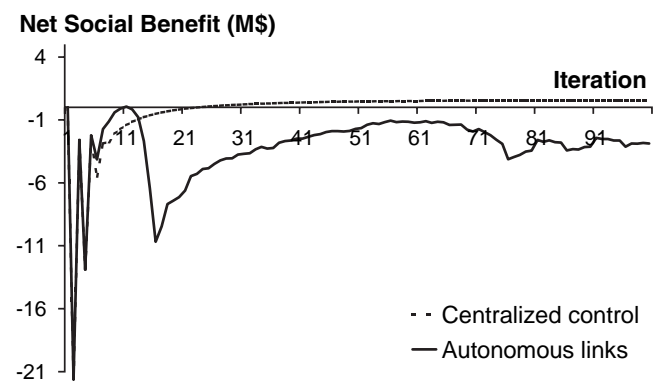

(e)

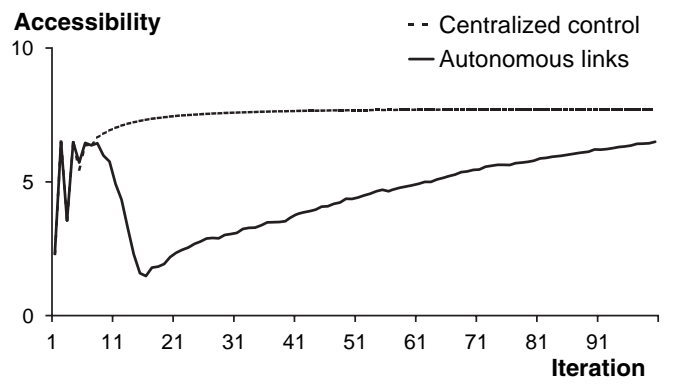

(b)

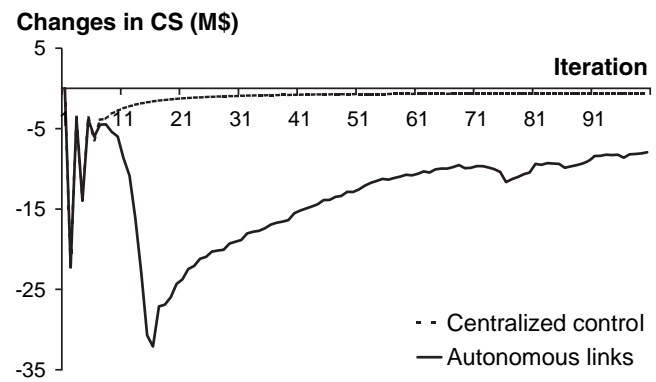

(d)

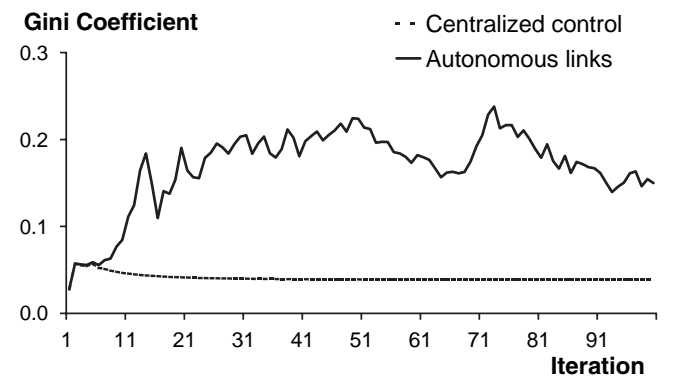

(f)

FIGURE 7 Results: measures of effectiveness. 
pricing and privatization that have not previously been seriously considered, and it compares welfare and profit consequences of alternative organizational structures. The proposed modeling system integrates an equilibrated travel demand, route choice, and travel time model with a repeated road pricing game between autonomous links. Although a game theoretical approach seems to be more appealing, it is extremely difficult to model the payoff structure in a general network. The agent-based system can serve as a test bed for assessing long-term consequences of various transportation network investment and pricing policies and institutional structures. Another possible application of the system is to explore "free" roads that compete with toll roads and the consequences of regulatory constraints. Although this paper focuses on highway networks, the agent-based simulation approach could be used to analyze other types of networks with appropriate demand and cost functions.

The existence of spatial monopoly, spatial dependence, and demand uncertainty may force independent links to adopt myopic nonoptimal pricing and investment strategies, which in turn results in inferior social welfare compared to centralized control. For the same reason, many autonomous links eventually lose money in the pricing game. Some degree of government intervention in the form of price ceilings or restrictions on road expansion may prevent overinvestment. However, this is not to say that a market solution to highway financing and pricing is worthwhile. Besides noncooperative independent links, there are alternative organizational structures that may improve both private and social welfare.

One limitation of the research is that cooperation among autonomous links is assumed away. Just as airline networks seem to have evolved a hub-and-spoke hierarchy, a specific geometry may be optimal in a private highway network. There may be advantages to both the private and social welfare if vertical integration of highly complementary links is allowed in the system. However, the degree of complementarity for which integration serves both public and private interests remains to be determined. As in other multiagent systems, the critical issue here is the behavior of the decision makers: the autonomous links. How do coalitions between links form? In what circumstances will links pursue revenue and cost sharing? An interlink negotiation process must be developed to answer these important questions. The link pricing rule itself may be adjusted in the evolutionary process through learning and adaptation. None of these efforts is easy work. However, it would be interesting to see what kind of organizational structure emerges to take advantage of economies of scale in the network.

\section{REFERENCES}

1. Gomez-Ibanez, J., and J. Meyer. Going Private: The International Experience with Transport Privatization. Brookings Institution, Washington, D.C., 1993.

2. Sheffi, Y. Urban Transportation Networks: Equilibrium Analysis with Mathematical Programming Methods. Prentice Hall, Englewood Cliffs, N.J., 1985.

3. Boyce, D. E., R. Farhi, and R. Weischedel. Optimal Subset Selection: Multiple Regression, Interdependence and Optimal Network Algorithms. Springer-Verlag, New York, 1974.
4. Rothengatter, W. Application of Optimal Subset Selection to Problems of Design and Scheduling in Urban Transportation Networks. Transportation Research, Vol. 13B, No. 1, 1979, pp. 49-63.

5. Johansson, B., C. Karlsson, and L. Westin (eds.). Patterns of a Network Economy. Springer-Verlag, Berlin, 1993.

6. Nagurney, A. Network Economics: A Variational Inequality Approach. Kluwer Academic Publishers, Norwell, Mass., 1993.

7. Economides, N. The Economics of Networks. International Journal of Industrial Organization, Vol. 16, No. 4, 1996, pp. 673-699.

8. Langton, C. (ed.). Artificial Life. Addison-Wesley, Redwood City, Calif., 1989.

9. Verhoef, E. T., and J. Rouwendal. Pricing, Capacity Choice, and Financing in Transportation Networks. Journal of Regional Science, Vol. 44, No. 3, 2004, pp. 405-435.

10. Ben-Akiva, M., and S. Lerman. Discrete Choice Analysis: Theory and Application to Travel Demand. MIT Press, Cambridge, Mass., 1985.

11. Train, K. Qualitative Choice Analysis: Theory, Econometrics, and an Application to Automobile Demand. MIT Press, Cambridge, Mass., 1986.

12. Newell, G. Applications of Queuing Theory, 2nd ed. Chapman and Hall, New York, 1982.

13. Levinson, D., D. Gillen, J. Mathieu, T. Reinhold, and A. Kanafani. The Full Cost of Intercity Transportation: A Comparison of Air, Highway, and High Speed Rail in California. Research Report UCB-ITS-RR-96-3. Institute of Transportation Studies, University of California-Berkeley, 1996.

14. Levinson, D., and R. Karamalaputi. Induced Supply: A Model of Highway Network Expansion at the Microscopic Level. Journal of Transport Economics and Policy, Vol. 37, No. 3, 2003, pp. 297-318.

15. Zhang, L., and D. Levinson. Agent-Based Approach to Travel Demand Forecasting: Exploratory Analysis. In Transportation Research Record: Journal of the Transportation Research Board, No. 1898, Transportation Research Board of the National Academies, Washington, D.C., 2004, pp. 28-36.

16. Zhang, L., and D. Levinson. A Model of the Rise and Fall of Roads. Presented at 50th North American Regional Science Council Annual Meeting, Philadelphia, Pa., Nov. 20-22, 2003.

17. Boyce, D. E. Is the Sequential Travel Forecasting Paradigm Counterproductive? Journal of Urban Planning and Development, Vol. 128, No. 4, December 2002, pp. 169-183.

18. Kitamura, R. An Evaluation of Activity-Based Travel Analysis. Transportation, Vol. 15, 1988, pp. 9-34.

19. Haynes, K. E., and A. S. Fotheringham. Gravity and Spatial Interaction Models. Sage Publications, Beverly Hills, Calif., 1984.

20. Hutchinson, B. G. Principles of Urban Transportation Systems Planning. McGraw-Hill, New York, 1974.

21. Bar-Gera, H., and D. Boyce. Origin-Based Algorithm for Combined Travel Forecasting Models. Transportation Research, Vol. 37B, No. 5 , 2003, pp. 405-422.

22. Wardrop, J. G. Some Theoretical Aspects of Road Traffic Research. Proc., Institution of Civil Engineers, Part II, Vol. 1, No. 36, 1952, pp. 325-362.

23. Arnott, R., A. de Palma, and R. Lindsey. Route Choice with Heterogeneous Drivers and Group-Specific Congestion Cost. Regional Science and Urban Economics, Vol. 22, No. 1, 1992, pp. 71-102.

24. Shmanske, A. A Simulation of Price Discriminating Tolls. Journal of Transport Economics and Policy, Vol. 27, No. 3, 1993, pp. 225-235.

25. Small, K. A., and J. Yan. The Value of "Value Pricing" of Roads: SecondBest Pricing and Product Differentiation. Journal of Urban Economics, Vol. 49, No. 2, 2004, pp. 310-336.

26. Zhang, L., and D. Levinson. Investing for Reliability and Security in Transportation Networks. Presented at 84th Annual Meeting of the Transportation Research Board, Washington, D.C., 2004.

The Road Pricing Subcommittee of the Taxation and Finance Committee sponsored publication of this paper. 